\title{
Possibility of Non-enzymatic mRNA Degradation in E. coli : I. Bell-shaped Kinetic Feature
}

\author{
Hyeong-Won Ryu ${ }^{*}$ and Thong-Sung Ko \\ The Institute of Science \& Technology, Mokwon University, Daejeon 302-729, Korea. "E-mail: howrnn@mokwonackr \\ Received June 27, 2006
}

Key Words : Nonenzymatic, $\mathrm{RN} \Lambda$ degradation, $m \mathrm{mN} \Lambda$, Bell shape

Although vigorous research efforts, aimed to understand the mechanism of mRNA degradation that is important in regulation of gene expression, have been directed entirely to RNases to identify putative mRNases since the discovery of the mRNA instability, the elucidation of the mRNA degradation mechanism has been the slowest process among principal gene regulatory processes in Escherichia coli..$^{1-3}$

In respect of shorter half-lives of prokaryotic mRNAs than those of eucaryotic mRNAs, ${ }^{3}$ a $5^{\prime}$-to- $3^{\prime}$ directionality of mRNA decay in accordance with the $5^{\prime}$-to-3' directionality of coupled transcription-translation in prokaryotes has been paid special attention. ${ }^{4}$ Formerly, in this line of research works, a putative ribosome-associated 5'-to-3' exoribonuclease (RNase V) had been proposed as an mRNase, but it is known that such a 5-to-3' exoribonuclease does not exist in $E$. coli ${ }^{6}$ Therefore, current models suggest that mRNA degradation is initiated by a certain endoribonuclease(s) (functional inactivation of message) and the subsequent degradation of resulting fragments is carried out by $3^{\prime}-$ to $-5^{\prime}$ exoribonucleases (mass decay). ${ }^{1,2}$

According to the case of polycistronic lac mRNA degradation ${ }^{7}$ it is initiated near the $5^{\prime}$ end and progressed in the net $5^{\prime}$-to-3' direction, and predominant cleavage sites are the phosphodiester bonds between pyrimidine and adenine residues $(e, g, \mathrm{U} \downarrow \mathrm{A}$ ). Furthemore, most of the mRNA degradation products in growing $E$. coli have $5-\mathrm{OH}$ ends. ${ }^{8}$ These specificities are also known to correspond to those of non-enzymatic hydrolysis of RNA, ${ }^{9}$ nonetheless, the possibility of non-enzymatic degradation was neglected. For example, an enzyme, RNase $M$ was proposed as a new mRNase candidate for the characteristic activity. ${ }^{8}$ However, it was failed to identify the structural gene for RNase $\mathrm{M}^{10}$

Again, in line of "only RNases degrade (inactivate) mRNA" concept, RNase $\mathrm{E}$ which is an essential enzyme carrying out $5 S$ rRNA maturation ${ }^{11}$ and a 5 -end-dependent endoribonuclease showing the sequence specificity of $\mathrm{A}+\mathrm{U}$ rich single-stranded regions, ${ }^{12}$ and RNase E-based degradosome assembly have attracted so much attention as altemative mRNase candidates. ${ }^{2.13}$ However, RNase E not only shows marked preference for cleaving RNA that carries a monophosphate group at the 5 end rather than a triphosphate or a hydroxyl, but also generates 5 -phosphate ends instead of 5$\mathrm{OH}$ ends (Fig. 1). ${ }^{6.9 .12 .14,15}$ In addition, the observation of rapid degradation of $r p s \mathrm{O}$ mRNA (ribosomal protein $\mathrm{S} 15$ mRNA) in a triple mutant (RNase $\mathrm{E}^{-}, \mathrm{PNPase}^{-}$, and RNase

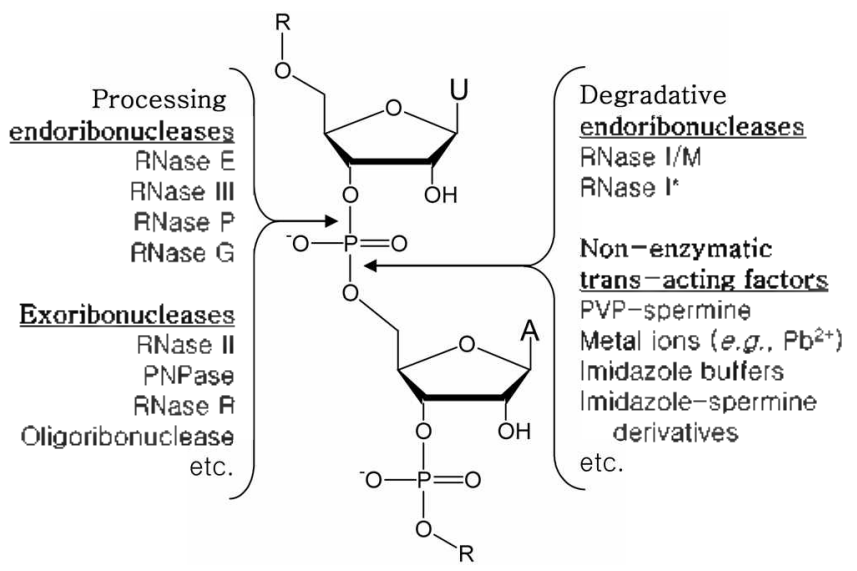

Figure 1. Specificities of $E$. coll RNases and non-enzymatic transacting factors in RNA phosphodiester bond cleavage.

$\left.\mathrm{E}^{-}\right)^{16}$ and of normal half-lives for several mRNAs in cells containing truncated forms of RNase $\mathrm{E}$ which preclude degradosome assembly, ${ }^{17}$ may indicate that RNase E and the degradosome assembly are irrelevant to the functional decay of mRNA.

Consequently, there is no obvious evidence to support the concept of "only RNases degrade mRNA". Three decades ago, in advance of the discovery of RNase-free self-cleavage activity of $\mathrm{RNA}^{18}$ a possibility of non-enzymatic $E$. coli $m R N A$ degradation mediated by protein biosynthetic machinery was proposed by $\mathrm{Ko}^{19}$ Recently, it has been discovered that translational pausing can promote endonucleolytic mRNA cleavage near the paused sites of ribosomes even in the absence of known endoribonucleases of $E$. coll ${ }^{20}$ This finding led in this field to suppose the possibility that ribosomes may be involved in the endonucleolytic cleavage event. $^{21}$

\section{Results and Discussion}

Construction of a simple simulation model. In order to investigate the degradation mechanism of $E$. coli $\mathrm{mRNA}$, we devised a simple simulation model possessed with elementary physicochemical key features of the protein synthetic machinery - mRNA interaction. We adopted the PVP (polyvinylpyrrolidone)-spermidine system, ${ }^{9}$ expected to have only nonspecific noncovalent binding groups instead of specific catalytic groups, as a ribosome-like trans-acting factor, and 
(A)

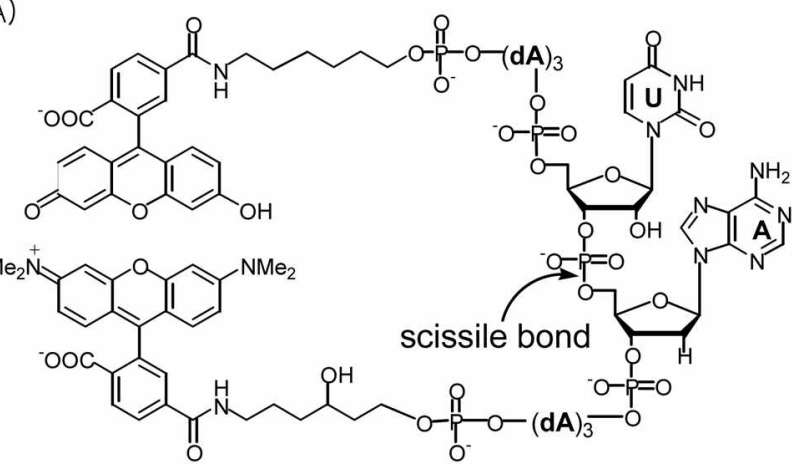

(B) Substrate 1: 6-FAM-dAdAdArUdAdAdAdA-6-TAMRA Substrate 2: 6-FAM-UUUUUUUUUU-6-TAMRA

Figure 2. (A) Chemical structure of fluorogenic substrate 1. (B) Nucleotide sequence of substrates, where 6-F $\Lambda \mathrm{M}$ and 6 -TAMR $\Lambda$ refer to 6-carboxyfluorescine and 6-carboxytetramethylrhodamine, respectively.

the chimeric oligonucleotide (substrate 1) containing a scissile bond (U $\downarrow \mathrm{A}$ ) as a model of functional mRNA with cis-acting elements, and the decameric U (substrate 2) as a reference of the mRNA model (Fig. 2).

Sequence irrespective bell-shaped curves and hypersusceptibility of UA sequence in non-enzymatic hydrolysis of oligoribonucleotides. In the hydrolytic cleavage of oligonucleotides catalyzed by the trans-acting PVP-spermidine system, both substrate 1 and substrate 2 showed bellshaped dependence on the concentration of PVP-spermidine, irrespective of the nucleotide sequence (Fig. 3). Although substrate $\mathrm{I}$, which has a scissile bond ( $\downarrow \downarrow$ A) for ribonucleolytic cleavage, has 9 times less such cleavable bonds than substrate 2 , the measured release rates of fluorescent products of the two substrates in the absence of

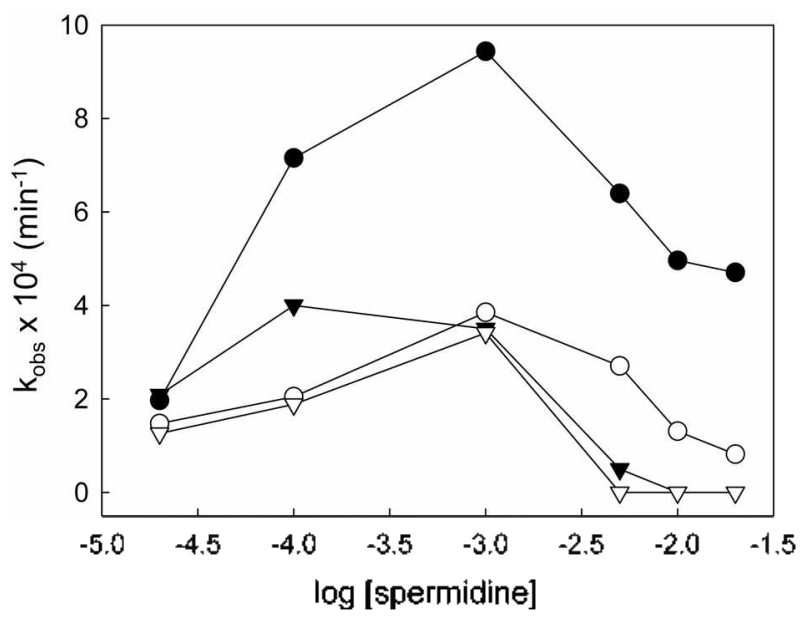

Figure 3. Dependence of the rate constants of hydrolytic cleavage of oligonucleotides on PVP-spermidine concentrations. The reactions were carried out in the presence $(0.2 \%)(\boldsymbol{O}, \boldsymbol{\nabla})$ and absence $(O, \nabla)$ of PVP under the conditions described in the Experimental Section. The substrate concentrations were $100 \mathrm{nM}$ (substrate I: $\odot, \bigcirc$ ) and $140 \mathrm{nM}$ (substrate $2: \nabla, \nabla$ ), respectively.
PVP were similar, possibly due to the instability of the UA phosphodiester bond of substrate 1 (uncatalyzed rate constant of the hydrolysis, $\mathrm{k}_{\mathrm{n}}=1.2 \times 10^{-4} \mathrm{~min}^{-1}$ ) compared to UU of substrate $2\left(\mathrm{k}_{4}=1.5 \times 10^{-5} \mathrm{~min}^{-1}\right){ }^{22}$ Moreover, in the presence of PVP, substrate 1 showed higher reactivity than substrate 2 . The bell-shaped curve and the hypersusceptibility of UA sequence to hydrolytic cleavage can be characteristic features of non-enzymatic RNA degradation. ${ }^{9}$

Protein synthetic machinery-mediated poly $(U)$ degradation and a bell-shaped curve. We revisited the previous report (Kuwano et al., Proc. Natl. Acad. Sci. USA 1969, 64, 693 ) on the degradation of poly(U) mediated by the cell-free protein synthetic machinery of $E$. coli. The data of Figure 4A (Fig. le in the original paper) ${ }^{\text {sa }}$ which show that the rate of poly $(\mathrm{U})$ degradation is increased by the increase of ribosome concentration, demonstrate that the ribosome component of protein biosynthetic machinery is necessary for the degradation. And, Figure 4B (Fig. 1c in the paper) ${ }^{5,}$ which shows that the rate of poly(U) degradation is inversely proportional to the concentration of $5^{\prime}-\beta, \gamma$-methyleneguanosine triphosphate (GMP-PCP), demonstrates that the stabilization of poly(U) from degradation is due to the stalled ribosomes on poly $(\mathrm{U})$ by blocked translocation caused by GMP-PCP, an unhydrolyzable GTP analogue which inhibits $G$ and $T$ factors needed for translation. This observed ribonucleolytic activity led them to propose an mRNase named as RNase V (5'-to-3' exoribonuclease), ${ }^{5}$ but nobody including them found such an enzyme, i.e., 5'-to-3' exoribonuclease, in $E$. coli ${ }^{6}$

One of the most naive explanation of the poly(U) degradation activity of ribosomes would be contamination of the ribosome component with certain RNases. In such a case, the degradation reaction should follow enzyme kinetics, showing a linearly increasing rate profile that is directly proportional to the ribosome concentration because of the

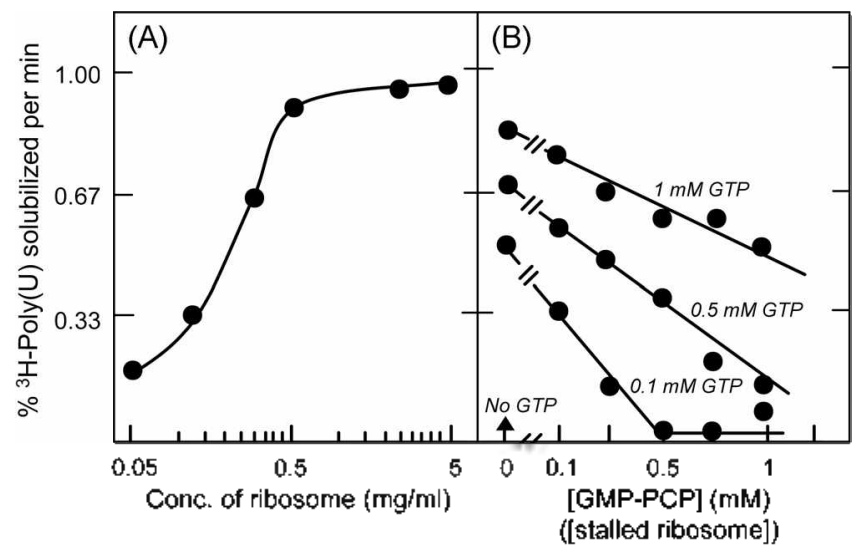

Figure 4. Dependence of poly(U) degradation on the concentration of ribosone $(A)$ and of GMP-PCP $(B)$ mediated by the cell-frec protein synthetic machinery of $E$. colt. In panel $\mathrm{B}$, the reactions were carried out in the presence of $2 \mathrm{mg} / \mathrm{ml}$ of ribosomes with varying concentrations of GTP, where the increase of GMP-PCP concentration with decreasing GTP corresponds to the increase of ribosome stalling on poly(U) by blocked translocation. The data was transferred from Kuwano et al. (1969) without permission of the authors. 
contamination. But in our present reexamination of their data (Fig. Ie plus Ic), we find that the degradation reaction kinetics is not that of an enzymatic reaction but that of a nonenzymatic reaction as shown in Figure 4: we can actually get a bell shape when the two panels are combined together (pane] A plus pane] B in Fig. 4).

Here, we can claim that the degradation reaction belongs to a non-enzymatic reaction instead of an enzymatic reaction. In addition, a study reported that the ribonucleolytic activity of $E$. coll cell-free protein synthetic machinery was insensitive to human placental RNase inhibitor, whereas removal of the $70 \mathrm{~S}$ ribosome fraction from complete assay mixtures prolonged the half-life of an mRNA. ${ }^{23}$ However, the putative RNase assumed to be associated tightly with ribosomes has been neither detected nor identified up to date. Therefore, it may be improbable to ascribe the ribonucleolytic activity observed in Figure 4 to any RNase contamination of the system.

Then, the trans-acting factor responsible for the poly(U) degradation ought to be ribosome itself. So far as we obtained an important clue that the mechanism of functional mRNA degradation can be that of non-enzymatic degradation by protein biosynthetic machinery, in which ribosomes act as a trans-acting factor, we were interested in experimental further verification of the non-enzymatic degradation mechanism. In our simulation model system employed for this purpose, in which PVP-spemidine functions as a trans-acting factor, the non-enzymatic degradation reaction system demonstrated a bell-shaped dependence on the concentration of PVP-spermidine (Fig. 3), just like the above protein synthetic machinery-mediated mRNA (poly(U)) degradation system (Fig. 4).

Effects of antibiotics on mRNA stability can be explained by the present model of non-enzymatic mRNA degradation. The antibiotics that have no influence on RNase action can exert profound effects on mRNA stability via their effects on ribosome - mRNA interaction. Puromycin, which strips fully extended mRNA of bound ribosomes, can cause scissile sites (e.g., $\mathrm{U} \downarrow \mathrm{A}$ ) to be exposed and the mRNA to be destabilized in hydrolytic environment. On the other hand, the protection of scissile sites from hydrolytic environment by the trans-acting stalled ribosomes, caused by fusidic acid and chloramphenicol which freeze ribosomes

Table 1. Effects of antibiotics on mRNA stability in $E$. coli ${ }^{i t}$

\begin{tabular}{ccccc}
\hline & \multicolumn{2}{c}{ Half-lives (min) } & \\
\cline { 2 - 3 } control & $\begin{array}{c}\text { ribosome } \\
\text { release }\end{array}$ & \multicolumn{2}{c}{$\begin{array}{c}\text { ribosome } \\
\text { freeze }\end{array}$} & $\begin{array}{c}\text { mRNA } \\
\text { species }\end{array}$ \\
\cline { 2 - 3 } & puromycin & fusidic acid chloramphenicol & \\
\hline 2.8 & 0.8 & & & lac mRNA \\
1.2 & 0.6 & 2.6 & & total mRNA \\
5.5 & 1.0 & & & trp mRNA \\
2.5 & & 9 & 18.5 & total mRNA \\
3.5 & & & 10 & lacZ mRNA \\
\hline
\end{tabular}

${ }^{2}$ Data were collected from the previously published reports. ${ }^{4}$
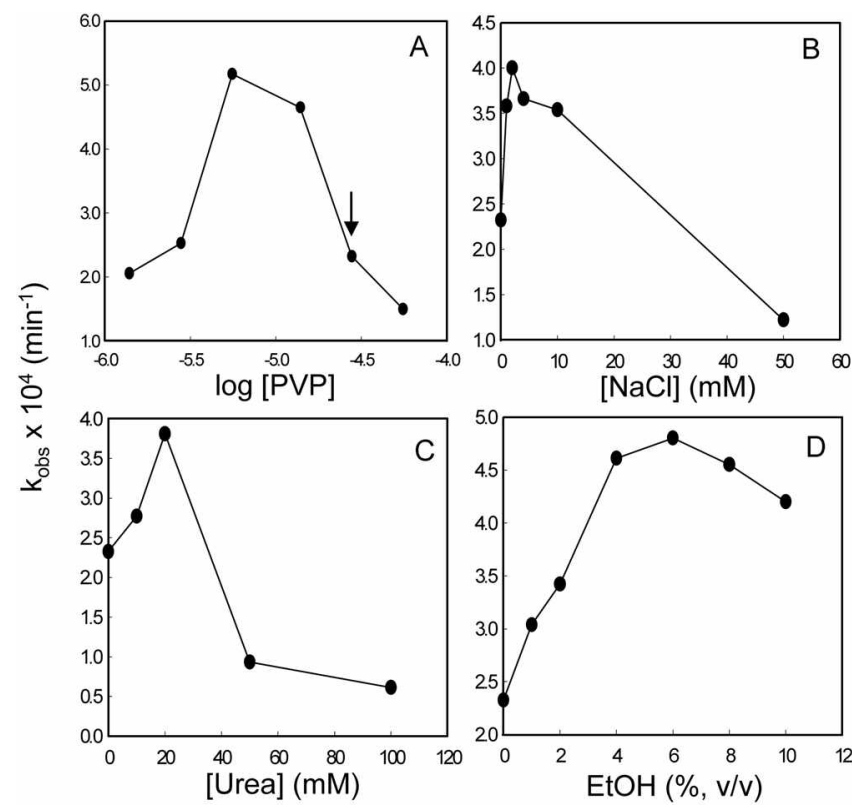

Figure 5. Effect of relieving the excessive binding interaction of the trans-acting PVP-spermidine system with oligonucleotides on its negative catalysis activity. (A) Plot of the rate constants of hydrolytic oligonuclcotide-cleavage $v s$. concentration of PVP. The reaction was performed with substrate $2(120 \mathrm{nM})$ in the presence of $1 \mathrm{mM}$ spermidine with increasing PVT concentration under the conditions described in the Experimental Section. Dependence of the hydrolytic clcavage activity of PVP-spermidine on the varying concentrations of sodium chloride (B), urea (C), and cthanol (D), respectively, was examined at the reaction conditions ( $1 \mathrm{mM}$ spermidine and $27.8 \mu \mathrm{M}$ PVP) indicated by the arrow in panel $A$.

on mRNA, can stabilize the mRNA. Thus the present model of non-enzymatic mRNA degradation can be supported by the observed effects of antibiotics on mRNA stability, and vice versa (Table 1$)^{4}$

To verify above assumption further, we examined the effect of relieving the excessive binding interaction of the trans-acting PVP-spermidine system with oligoribonucleotides on its negative catalysis activity (Fig. 5). Expectedly, as the result of the addition of varying concentrations of sodium chloride, urea, and ethanol, respectively, at the reaction condition of the excessive binding interaction (containing 1 $\mathrm{mM}$ spermidine and $27.8 \mu \mathrm{M}$ PVP) indicated by the arrow in panel A of Figure 5, another bell shape in each case was obtained (panel B-D of Fig. 5).

The observations that even widely spaced translating ribosomes are able to contribute to the mRNA stability and stalled ribosomes are especially effective for protecting mRNA from degradation, ${ }^{3}$ can not be explained by the current concept that is entirely limited to the ribosomal steric barricade effect to keep off accessible RNases. ${ }^{24}$ However, our present model, i.e, the mechanism of protein biosynthetic machinery-mediated non-enzymatic degradation of $E$. coli $\mathrm{mRNA}$ as also proposed by Ko previously, ${ }^{19}$ may provide the answer to the perplexing problem for the role of ribosomes in mRNA stability as discussed above.

The characteristics that the non-enzymatic scissile site, 
$\mathrm{U} \downarrow \mathrm{A}$, is the primary cleavage site of $E$, coli mRNA and the $5 '-O H$ end generated by non-enzymatic degradation reactions is that of most mRNA degradation products of $E$. coli, may also support our suggestion of the mechanism of nonenzymatic (non-RNase) degradation. Here, we can also suppose that the activities, named as RNase M and RNase E which cause cleavage at the $U \downarrow$ A site, may probably be those of non-RNase trans-acting factors acting on the mRNA sequence. In conclusion, we suggest the possibility of non-enzymatic (non-RNase) rather than enzymatic (RNase) degradation in functional inactivation of mRNA in E. coli.

\section{Experimental Section}

The hydrolytic cleavage assay of oligonucleotides was performed with dual-labeled fluorogenic oligonucleotides (Integrated DNA Technology, USA) based on FRET (fluorescence resonance energy transfer). ${ }^{25}$ Fluorescence emission intensity was measured at $518 \mathrm{~nm}$ (slit width $10 \mathrm{~nm}$ ) upon excitation at $490 \mathrm{~nm}$ (slit width $10 \mathrm{~nm}$ ) using a Perkin-Elmer spectrofluorometer and spectra were recorded with a scan speed of $100 \mathrm{~nm} / \mathrm{min}$ using a $0.3-\mathrm{cm}$ path length rectangular cell at room temperature. The reactions were carried out with shaking at $37^{\circ} \mathrm{C}$ for eight hours in $500 \mu \mathrm{L}$ of $50 \mathrm{mM}$ Tris buffer, $\mathrm{pH} 7.5$, containing $1 \mathrm{mM}$ EDTA, $100-140 \mathrm{nM}$ substrate, $0-3 \%$ PVP (PVP 360, RNase free, Sigma Chemical $\mathrm{Co}$.), and $0-50 \mathrm{mM}$ spermidine (Sigma). To determine rate constants, the maximum fluorescence intensity of product $\left(\mathrm{I}_{\max }\right)$ was measured with the addition of sufficient RNase A (type 1-AS, Sigma) to cleave all the substrate molecules. The fluorescence intensity of substrate $\left(\mathrm{I}_{0}\right)$ was measured prior to the addition of RNase A. From the fluorescence intensity of each sample $\left(I_{s}\right)$, the concentration of product ([P]) was determined from the equation, $\left[\mathrm{P}=[\mathrm{S}]_{\text {iotal }} \times(\Delta \mathrm{I} /\right.$ $\left.\Delta \mathbf{I}_{\text {max }}\right)$; here, $[\mathrm{S}]_{\text {lotal }}=$ total substrate concentration, $\Delta \mathrm{I}_{\text {max }}=$ $\mathrm{I}_{\text {nax }}-\mathbf{I}_{0}$, and $\Delta \mathbf{I}=\mathbf{I}_{\mathrm{s}}-\mathrm{I}_{0}$, respectively. The pseudo first-order rate constants $\left(\mathrm{k}_{\mathrm{obs}}\right)$ were determined from $\mathrm{k}_{\mathrm{obs}}=[\mathrm{P}] / \Delta \mathrm{t} /$ $[S]_{\text {lotal }}$. The kinetic runs were performed in duplicate (Fig. 5) or triplicate (Fig. 3) and the reproducibility of the data was better than $\pm 7 \%$.
Acknowledgement. This work was supported by the Korea Research Foundation Grant (KRF-2004-075-C00009).

\section{References}

I. Kennell, D. J. Bacteriol. 2002, $184,4645$.

2. Kushner, S. R. J. Bacteriol. 2002, 184, 4658 .

3. Belasco J. G. mRNA Degradation in Prokanotic Cells: An Overview in Control of Messenger RNA Stability; Belasco, J. G. Brawerman, Gi, Eds.; Academic Press: San Diego, CA, 1993;p 3.

4. Petersen, C. Translation and mRNA Stability in Bacteria: A Complex Relationship in Control of Messenger RNA Stability; Belasco, J. G; Brawerman, G., Eds.; Academic Press: San Diego, CA, 1993 ; p 117 .

5. (a) Kuwano, M.; Kwan, C. N.; Apirion, D.; Schlessinger, D. Proc. Natl. Acad. Sci. USA 1969, 64, 693. (b) Kuwano, M.; Schlessinger, D.; Apirion, D. J. Mol, Biol. 1970, 51, 75.

6. Deutscher, M. P. J. Biol. Chem. 1993, 268, 13011.

7. (a) Cannistraro, V. J.; Subbarao, M. N.; Kennell, D. J. Mol. Biol. 1986, 192, 257. (b) Cannistraro, V. J.; Kennell, D. Evrr. J. Biochem. 1989, 181, 363 .

8. Cannistraro, V. J.; Kennell, D. Eur. J. Biochem, 1993, 213, 285.

9. Kierzek, R, Methods Enzymol. 2001, 341,657.

10. Subbarayan, P. R.; Deutscher, M. P. RNA 2001, 7, 1702.

11. Ghora, B. K.; Apirion, D. Cell 1978, 15, 1055.

12. Mackie, G. A. Nature 1998, 395, 720.

13. Vanzo, N. F.; Li, Y. S.; Py, B; Blum, E.; Higgins, C. F.; Raynal, L. C.; Krisch, H. M.; Carpousis, A. J. Genes Dev: 1998, 12, 2770.

14. Jiang, X; Belasco, J. G Proc, Natl. Acad. Sci. USA 2004, 101, 9211 .

15. (a) Breslow, R. Acc. Chent. Res. 1991, 24,317. (b) Vlassov, V. V.; Zuber, G.; Felden, B.; Behr, J. P.; Giege, R. Nicleic Acids Res. $1995,23,3161$.

16. Hajnsdorl, E.; Steier, O.; Coscoy, L.; Teysset, L.; Regnier, P. EMBO J. 1994, 13, 3368.

17. Ow, M. C.; Liu, Q.; Kushner, S. R. Mol. Microbiol. 2000, 38,854

18. Grabowski, P. J.; Zaug, A. J.; Cech, T. R. Cell 1981, 23, 467.

19. Ko, T.-S. Biosystents 1975, 6, 205.

20. Sunohara, T.; Jojima, K.; Tagami, H.; Inada, T.; Aiba, H. J. Biol. Chem, 2004, 279, 15368.

2l. Baker, K. E.; Condon, C. RNA 2004, $10,1680$.

22. Kaukinen, U.; Lyytikäinen, S.; Mikkola, S.; Lönnberg, H. Nucleic Acids Res. 2002, 30,468

23. Fuchs, U.; Stiege, W.; Erdmann, V. A. FEBS Leff. 1997, 414, 362.

24. Deana. A.; Belasco, J. G Genes Dev: 2005. 19, 2526.

25. Park, C.; Kelemen, B. R.; Klink, T. A.; Sweeney, R. Y.; Behlke, M. A.; Eubanks, S. R.; Raines, R. T. Methods Enzymol. 2001, 341, 81. 